\title{
Epidemiologia dos dados antropométricos de crianças e adolescentes com Doença Falciforme na região de Feira de Santana-BA
}

\author{
Ana Carolina Silva Assuncãó ${ }^{1}$; Carina Oliveira Silva Guimarães²; Heros Aureliano \\ Antunes da Silva Maia ${ }^{3}$ e Anna Paloma Martins Rocha Ribeiro ${ }^{4}$ \\ 1. Voluntária PEVIC/CNPq, Graduanda em Medicina, Universidade Estadual de Feira de Santana, e-mail: \\ anacarolina_assuncao@hotmail.com \\ 2. Programa de Pós Graduação em Saúde Coletiva, Universidade Estadual de Feira de Santana, e-mail: \\ carioliveira13@outlook.com \\ 3. Participante do núcleo UROS e subgrupos populacionais, Departamento de saúde, Universidade Estadual de Feira de \\ Santana, e-mail: herosmaia@hotmail.com \\ 4. Orientadora, Departamento de saúde, Universidade Estadual de Feira de Santana, e-mail: lominharibe@yahoo.com.br
}

PALAVRAS-CHAVE: antropometria; doença falciforme; epidemiologia

\section{INTRODUÇÃO}

A doença Falciforme (DF) é a doença genética mais incidente em nosso país, com destaque para o estado da Bahia, acomete principalmente afrodescendentes. Pode acarretar inúmeras complicações sistêmicas através de processos hemolíticos e vaso-oclusivos. Além de impactos físicos, a DF implica também de forma significativa na qualidade de vida dessas pessoas.

A composição corporal é alterada de forma significativa durante a transição da infância para adolescência. Segundo Odetunde et al. (2016), hipoxemia e hipoperfusão tecidual são aspectos significativos e afetam o metabolismo tecidual de quase todos os sistemas do corpo humano, causando atraso no crescimento e no desenvolvimento.

Segundo Nandanwar e Kamdi (2013), crescimento e desenvolvimento afetados fornecem evidências inequívocas de comprometimento em várias medidas antropométricas como altura, peso, composição corporal e maturação sexual e esquelética.

De acordo com Oredugba (2002), a presença de doença crônica, a circulação sanguínea hiperdinâmica e outros processos mal definidos na DF contribuem para alterações nas medidas antropométricas, devido ao infarto prévio das extremidades crescentes dos ossos antes que as epífises se unam. Os vasos sanguíneos bloqueados podem causar dor, infecção grave e danos aos órgãos.

Percebe-se que, o conhecimento da epidemiologia acerca dos dados antropométricos em associação com a DF na população pediátrica é de grande valia no contexto público de saúde. O monitoramento do crescimento, segundo Odetunde et al. (2016) em crianças com DF é uma ferramenta vital para cuidados abrangentes, o que facilita o diagnóstico precoce de falhas de crescimento e intervenção nutricional. Por isso, a compreensão destes aspectos possibilitará ações de saúde mais eficientes além de minimizar os agravos relacionados à tão sofrida condição.

\section{METODOLOGIA}

Trata-se de estudo transversal observacional (cross-sectional) com pacientes pediátricos (idades entre 06 a 18 anos de idade) de ambos os sexos com DF, acompanhados em Centro de referência à pessoa com DF no município de Feira de Santana-BA. Após assinatura do TCLE em conformidade com a Resolução 466/12, os sujeitos responderam a questionário estruturado acerca das características sociodemográficas e avaliação antropométrica (peso e altura). O peso foi aferido em balança de alta precisão da marca Filizola de uso hospitalar, estando calibrada em zero no momento da pesagem e a altura foi obtida através do estadiômetro vertical, graduado em décimos de centímetros, conforme às normas descritas por Lohman (1988). O IMC foi obtido a partir da divisão do peso corporal em quilogramas $(\mathrm{Kg})$, pela altura em metro $(\mathrm{m})$, elevada ao quadrado $(\mathrm{IMC}=$ peso/altura2). Para avaliar o estado nutricional antropométrico, 
foi utilizado o indicador índice de massa corporal/idade (IMC/I). Para a análise dos escores-z foram utilizados o software OMS Anthro e AnthroPlus 1.0.4. (WHO, 2009). Os pontos de corte adotados para os indicadores antropométricos foram: eutróficas (escore-z $>-2 \mathrm{e}<1$ ), magreza (escore-z -2 a -3) ou magreza acentuada (escore-z $<-3$ ), sobrepeso (escore-z +1 a +2 ) e obesidade (escore-z >+2) (WHO, 2006). As variáveis quantitativas, contínuas ou ordinais, foram descritas por suas medidas de tendência central (médias ou medianas) e pelas respectivas medidas de dispersão (desvio-padrão, variação interquartil ou valores mínimo e máximo), enquanto as nominais ou qualitativas por seus valores absolutos, percentagens ou proporções. Para comparação das diferenças das variáveis contínuas, utilizamos o teste $t$ de Student ou o teste de Mann-Whitney. Teste de D'Agostino - Pearson foi empregado na avaliação do padrão de distribuição das variáveis. Na comparação dos dados categóricos, utilizamos os testes de Fisher ou do qui-quadrado e suas variantes. Valores de $p$ menores que $0,05(\mathrm{p}<0,05)$ foram considerados significativos. Nas análises foi utilizado o programa estatístico computacional GraphPad Prism, versão 6.0.3, GraphPad Software, San Diego-CA, USA. O estudo foi aprovado pelo comitê de ética em Pesquisa da Universidade Estadual de Feira de Santana-BA (CAAE: 70227617.4.0000.0053), atendendo às normas previstas na resolução do Conselho Nacional de Saúde no 466/2012.

\section{RESULTADOS E DISCUSSÃO}

$\mathrm{O}$ estudo incluiu 93 crianças e adolescentes, das quais 52 eram do sexo feminino. $\mathrm{O}$ genótipo mais frequente foi o SS em $53,76 \%$. As características sociodemográficas estão mais bem detalhadas na tabela 1:

Tabela 1: Características sociodemográficas e clínicas das crianças e adolescentes com doença falciforme, no município de Feira de Santana, BA.

Característica
Sexo
Feminino
Masculino
Genótipo
SS
SC
SF
Raça/Cor
Amarelo
Branco
Preto
Pardo
Vermelho
Renda Familiar -Salários mínimos
$<1$ SM
1 SM
$>1 S M$

$\begin{array}{ll}\mathrm{n}(93) & \% \\ 52 & \\ 41 & 55,91 \\ & 44,08 \\ 50 & \\ 42 & 53,76 \\ 1 & 45,16 \\ & 1,07 \\ 1 & \\ 6 & 1,08 \\ 44 & 6,45 \\ 42 & 47,31 \\ 0 & 45,16 \\ & 0,00 \\ 26 & \\ 45 & 27,95 \\ 22 & 48,39 \\ & 23,65\end{array}$

$65(70 \%)$ das crianças apresentavam-se eutróficas, enquanto13(14\%) apresentavam magreza ou magreza acentuada. Sobrepeso ou obesidade foi observado em 15(16\%). A distribuição dos dados está demonstrada na figura a seguir: 


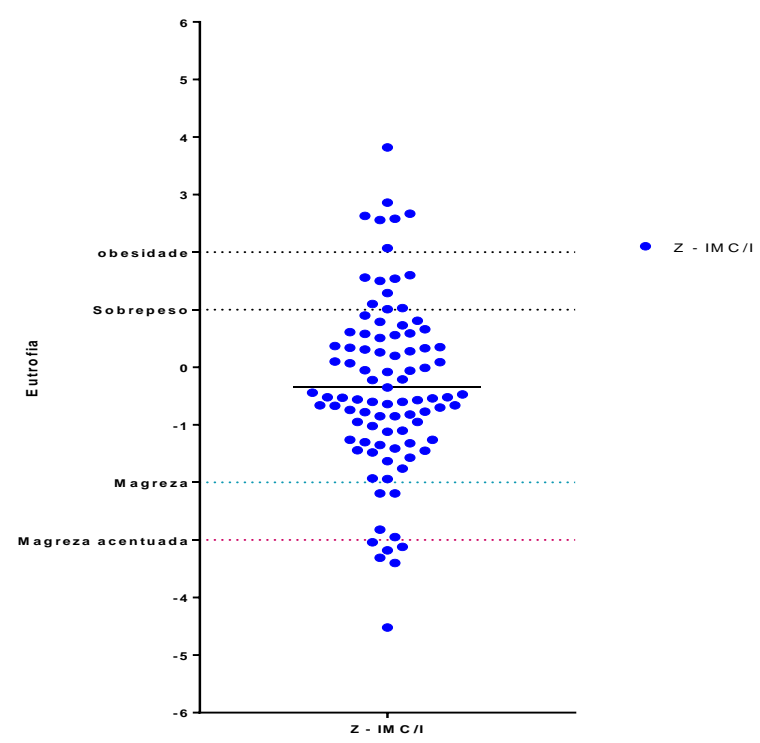

Figura 1: Diagnóstico nutricional em crianças e adolescentes com doença falciforme, no município de Feira de Santana, BA.

$\mathrm{O} z$ escore do IMC/I foi significativamente maior nos genótipos heterozigotos $\mathrm{HbSC} / \mathrm{SF}$ quando comparados aos homozigotos HbSS, conforme a figura 2.

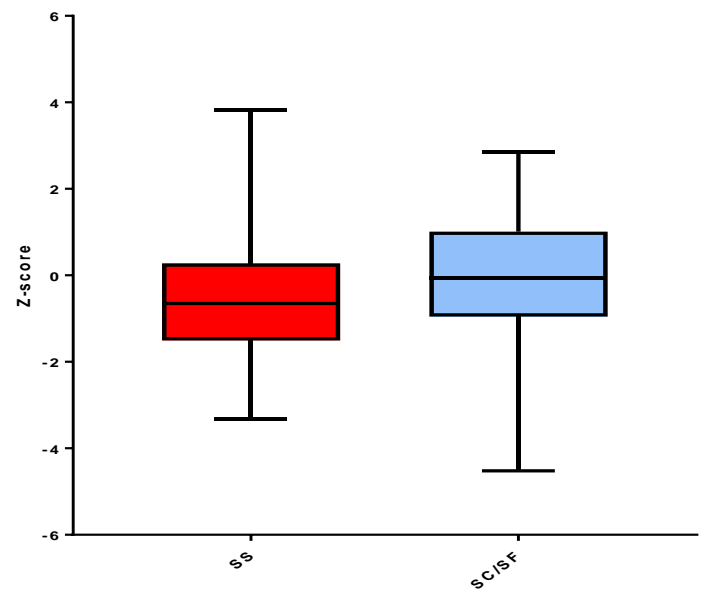

Figura 2: Escore-z do índice de Massa corporal por idade em crianças e adolescentes de acordo com a expressão da hemoglobina S com doença falciforme, no município de Feira de Santana, BA.

Estudos similares como o de Lukusa Kazadi et al (2017), mostrou que em um grupo de 256 pacientes, 53,9\% eram mulheres e 47,7\% das crianças tinham baixo peso. Ao comparar pacientes com DF com um grupo de $\mathrm{Hb}$ normal, houve uma proporção significativamente maior de indivíduos com baixa estatura e déficit de peso.

Chawla et al. (2013), coletaram dados com 675 crianças e adolescentes em 3 estados da Nova Inglaterra, EUA. Nesta amostra, 22,4\% apresentavam sobrepeso ou obesidade, enquanto $6,7 \%$ estavam abaixo do peso. O estado antropométrico de sobrepeso ou obeso foi associado a genótipos falciformes heterozigóticos.

Esezobor et al. (2016) participaram do estudo 233 crianças, 60,9\% do sexo masculino. As taxas de desnutrição, déficit estatural e sobrepeso ou obesidade foram de $22,7 \%, 11,6 \%$ e $1,7 \%$, respectivamente. Meninos e crianças de baixa classe socioeconômica foram 3,25 e 2,42 vezes mais chances de serem desnutridos, respectivamente. Tanto a desnutrição quanto o nanismo foram mais comuns com o aumento da idade. O sobrepeso ou a obesidade é incomum.

No nosso estudo, houve uma maior prevalência do sexo feminino conforme Lukasi Kazadi et al. (2017). Além disso, há uma frequência maior de indivíduos com Hb SS que é a 
forma mais grave da doença, raça/cor autodeclarada preto e renda familiar igual a 1 salário mínimo. Com relação ao IMC, a maioria das crianças e adolescentes eram eutróficas. Concomitantemente a isso, crianças e adolescentes com genótipo SS quando comparados aos $\mathrm{SC}$ e SF, parecem ter uma tendência maior para magreza/magreza acentuada. Enquanto, com relação a sobrepeso/obesidade, SC e SF têm maior tendência do que os SS conforme Chawla et al. (2013). No entanto, nos estudos de Odetunde et al. (2016) e Esezobor et al. (2016) houve maior prevalência de magreza/magreza acentuada na amostra total. Essa variação provavelmente se deve a aspectos amostrais, fatores ambientais e genéticos que limitam a comparabilidade entre esses estudos.

Segundo Nogueira et al. 2014, a DF apresenta alterações multissistêmicas e heterogêneas. As crises álgicas, maior susceptibilidade às infecções e hemólise crônica são fatores que contribuem para que crianças e adolescentes apresentem maior gasto energético em repouso e ingestão calórica reduzida, mesmo em períodos assintomáticos. Isso resulta em um desbalanço energético, déficits antropométricos e alterações na composição corporal, influenciados pelo genótipo, persistência de hemoglobina fetal elevada, acesso à assistência médica, cuidados pessoais, hidratação, alimentação e condição socioeconômica.

\section{CONSIDERAÇÕES FINAIS}

Os achados epidemiológicos revelam que em crianças e adolescentes há uma prevalência de indivíduos eutróficos, embora exista coexistência de ambos os extremos do estado nutricional antropométrico, magreza e excesso de peso, demonstrando a heterogeneidade das apresentações clínicas observadas nessa população. Crianças e adolescentes com a forma mais grave, homozigóticos (SS), apresentaram mais graves diminuição do peso corporal quando comparados aos heterozigóticos (SC/SF).

\section{REFERÊNCIAS}

AKODU, S.O. et al. Cormic Index Profile of Children with Sickle Cell Anaemia in Lagos, Nigeria. Anemia, Lagos, Nigeria, v. 2014, n. 1, p.1-6, 17 abr. 2014. Hindawi Limited.

BRASIL. Manual de Diagnóstico e Tratamento de Doença Falciformes. - Brasília : ANVISA, 2001.

CHAWLA, A. et al. Weight Status of Children With Sickle Cell Disease. Pediatrics, v. 131, n. 4, p. e1168-e1173, 2013.

ESEZOBOR, C.I.; et al. Wasting and stunting are still prevalent inchildren with sickle cell anaemia in Lagos, Nigeria. Italian Journal of Pediatrics. 2016.

FERNANDES, et al. Socioeconomic and demographic characteristics of sickle cell disease patients from a low-income region of northeastern Brazil. Revista Brasileira de Hematologia e Hemoterapia, 37(3), 172-177, 2015.

LUKUSA KAZADI, A. et al. Factors associated with growth retardation in children suffering from sickle cell anemia: First report from central Africa. Anemia, v. 2017.

NANDANWAR, R. A.; KAMDI, N. Y.. Sickle cell disease affects physical growth. International Journal Of Pharma And Bio Sciences, [s.i.], v. 2, n. 4, p.784-789, abr. 2013.

ODETUNDE, O. I. et al. Body Mass Index and other anthropometric variables in children with sickle cell anaemia. Pakistan Journal of Medical Science, v. 32, n. 2, p. 341346, 2016.

OREDUGBA, F.A. et al. Anthropometric findings in Nigerian children with sickle cell disease. Pediatric Dentistry, Lagos, Nigéria, v. 1, n. 24, p.321-325, abr. 2002.

THOMAS, P.W. et al. Height and weight reference curves for homozygous sickle cell disease. Archives Of Disease In Childhood, [s.i.], v. 1, n. 82, p.204-208, jan. 2000.

WHO Child Growth Standards. WHO Child Growth Standards Length/height-for-age, weight-for-age, weight-for-length, weight-for-height and body mass index-for-age Methods and development. 2006. 